\title{
Inter-Calibration of Satellite Passive Microwave Land Observations from AMSR-E and AMSR2 Using Overlapping FY3B-MWRI Sensor Measurements
}

\author{
Jinyang Du ${ }^{1,2 *}$, John S. Kimball ${ }^{1,2}$, Jiancheng Shi ${ }^{3}$, Lucas A. Jones ${ }^{1,2}$, Shengli Wu ${ }^{4}$, \\ Ruijing Sun ${ }^{4}$ and Hu Yang ${ }^{5}$
}

1 Flathead Lake Biological Station, The University of Montana, Polson, MT 59860, USA;

E-Mails: johnk@ntsg.umt.edu (J.S.K.); lucas@ntsg.umt.edu (L.A.J.)

2 Numerical Terradynamic Simulation Group, The University of Montana, Missoula, MT 59812, USA

3 Institute of Remote Sensing and Digital Earth, Chinese Academy of Sciences,

Beijing 100101, China; E-Mail: shijc@radi.ac.cn

4 National Satellite Meteorological Center, Beijing 100081, China;

E-Mails: wus1@cma.gov.cn (S.W.); sunrj@cma.gov.cn (R.S.)

5 Earth System Science Interdisciplinary Center (ESSIC), University of Maryland, 5825 University Research Court, Suite 4001, College Park, MD 20740-3823, USA;

E-Mail: huyang@umd.edu

* Author to whom correspondence should be addressed; E-Mail: jinyang.du@ntsg.umt.edu; Tel.: +1-406-982-3301; Fax: +1-406-982-3201.

Received: 22 May 2014; in revised form: 1 September 2014 / Accepted: 10 September 2014 / Published: 16 September 2014

Abstract: The development and continuity of consistent long-term data records from
similar overlapping satellite observations is critical for global monitoring and environmental
change assessments. We developed an empirical approach for inter-calibration of satellite
microwave brightness temperature $\left(T_{b}\right)$ records over land from the Advanced Microwave
Scanning Radiometer for EOS (AMSR-E) and Microwave Scanning Radiometer 2
(AMSR2) using overlapping $T_{b}$ observations from the Microwave Radiation Imager
(MWRI). Double Differencing (DD) calculations revealed significant AMSR2 and MWRI
biases relative to AMSR-E. Pixel-wise linear relationships were established from
overlapping $T_{b}$ records and used for calibrating MWRI and AMSR2 records to the AMSR-E
baseline. The integrated multi-sensor $T_{b}$ record was largely consistent over the major
global vegetation and climate zones; sensor biases were generally well calibrated, though 
residual $T_{b}$ differences inherent to different sensor configurations were still present. Daily surface air temperature estimates from the calibrated AMSR2 $T_{b}$ inputs also showed favorable accuracy against independent measurements from 142 global weather stations $\left(R^{2} \geq 0.75, R M S E \leq 3.64{ }^{\circ} \mathrm{C}\right)$, but with slightly lower accuracy than the AMSR-E baseline $\left(R^{2} \geq 0.78, R M S E \leq 3.46^{\circ} \mathrm{C}\right)$. The proposed method is promising for generating consistent, uninterrupted global land parameter records spanning the AMSR-E and continuing AMSR2 missions.

Keywords: brightness temperature; inter-calibration; AMSR-E; AMSR2; MWRI

\section{Introduction}

Microwave radiometers onboard Earth observing satellites have been widely used for observing critical land surface parameters supporting environmental monitoring and global change studies [1-4]. High-quality and consistent geophysical retrievals from well-calibrated, stable radiometer observations and long-term data records are essential for accurately delineating regional patterns and distinguishing natural climate variations from more subtle environmental trends.

The Advanced Microwave Scanning Radiometer for EOS (AMSR-E) was operational on board the NASA Aqua satellite from June 2002 to October 2011 and provided vertically and horizontally polarized, multi-frequency brightness temperature $\left(T_{b}\right)$ observations of the global land surface at 1-3 day intervals [5]. A variety of global land products and geophysical retrievals have been derived from the AMSR-E $T_{b}$ record, including atmosphere precipitable water vapor, surface air temperature, open water inundation, surface soil moisture, landscape freeze-thaw status, snow water equivalent, and vegetation canopy biomass optical depth [6-16]. These products have been refined through ongoing evaluations and reprocessings of the AMSR-E record to support global water, energy and carbon cycle studies [17-21].

The NASA AMSR-E sensor ceased operations in October 2011 due to a failure of the rotational antenna spin mechanism, while continuing observations from the AMSR2 sensor onboard the JAXA GCOM-W1 (Global Change Observation Mission 1st-Water) satellite began in May 2012 and effectively replaces AMSR-E [22]. In principle, similar geophysical retrieval algorithms from AMSR-E can be applied to AMSR2 since the two sensors have similar configurations including frequency, overpass time, and spatial resolution; these cross-sensor synergies facilitate the development of consistent long-term data records needed by the science community. However, AMSR-E and AMSR2 have differing sensor calibration and design characteristics, and non-overlapping operational records that potentially constrain development of consistent long-term data records from these sensors. Careful inter-comparison and inter-calibration of the AMSR (henceforth referring to AMSR-E and AMSR2 collectively) observations are a pre-requisite for developing consistent land parameter retrievals encompassing both sensor records.

Besides AMSR-E and AMSR2, post-launch radiometer calibration and validation (Cal/Val) activities have been underway for many years involving similar sensors, including the Defense Meteorological Satellite Program (DMSP) Special Sensor Microwave Imager (SSM/I) [23,24], Tropical Rainfall Measuring Mission Microwave Imager (TRMM TMI) [25], and the recent Global Precipitation 
Measurement (GPM) mission [26]. As summarized in [27], the methodologies involved in sensor inter-calibration activities can be classified into three general groups: (1) the simultaneous nadir overpass (SNO) approach; (2) statistical inter-calibration; and (3) double differencing (DD) methods. The statistical inter-calibration approach compares sensor observations directly, and calibrates the target instrument data using empirical models developed from multiple (e.g., thousands) collocated observations; this approach is best suited for two instruments having collocated and near simultaneous observations. On the other hand, for instruments without acceptable collocation thresholds, the DD method, which utilizes an intermediate reference such as a third instrument or radiative transfer model (RTM), is often applied [27]. The AMSR sensors have non-overlapping operational records, without temporally collocated $T_{b}$ observations; however, the DD method can be applied using an intermediate reference common to these records to quantify collocated $T_{b}$ differences for consistent calibration of the AMSR-E and AMSR2 records. An advantage of the DD method is that the calibration is less likely to be affected by sensor configuration differences, including incident angle and central frequency of the $T_{b}$ retrievals.

A critical issue affecting AMSR inter-calibration is a temporal gap of approximately nine months between the end of AMSR-E operations and subsequent initiation of the AMSR2 data record. Spatially collocated $T_{b}$ observations from the two radiometers are inappropriate for direct comparisons due to temporally dynamic land and atmosphere parameters. Therefore, current inter-calibration efforts for AMSR-E and AMSR2 are based on the general DD method. Preliminary inter-calibration results for AMSR2 have been reported from the Intersatellite Radiometer Calibration Working Group (XCAL) and JAXA [28,29]. Their approach involves using RTM simulations as an intermediate reference for calibrating AMSR2 $T_{b}$ retrievals, while selecting TMI or WindSat as the baseline sensor.

We adopted an alternative calibration approach aimed at producing consistent $T_{b}$ and resulting land surface air temperature estimates extending from the AMSR-E to AMSR2 portions of record. The calibration process utilized the DD method and a third microwave radiometer record with collocated observations to both AMSR-E and AMSR2 to calibrate AMSR2 $T_{b}$ observations to the earlier AMSR-E baseline record. The reference sensor used for calibration is the MWRI (Microwave Radiation Imager) on-board the Chinese FengYun 3B (FY3B) satellite, which was launched in November 2010 [30]. Similar overlapping MWRI observations to both AMSR-E and AMSR2 provided a unique opportunity for comparing and calibrating the sensor records. The MWRI has a similar instrument configuration and nearly simultaneous satellite overpass and data acquisition times as the AMSR sensors (i.e., 1:40 p.m./a.m. and 1:30 p.m./a.m. ascending/descending orbital nodes for MWRI and the AMSR sensors, respectively). The similar MWRI and AMSR overpass times mitigate potential $T_{b}$ differences from diurnal changes relative to other potential reference sensors with different overpass times, including WindSat ( $\sim \mathrm{AM} / \mathrm{PM})$ and TMI (variable overpass time). The descriptions of the sensors and datasets used in this investigation are presented in Section 2, while the calibration process and validation results are described in Sections 3 and 4. 


\section{Instruments and Data}

\subsection{Instrument Similarities and Differences}

AMSR-E on NASA's EOS Aqua satellite was launched 4 May 2002 and operated until 4 October 2011. As the successor to AMSR-E, AMSR2 on-board the sun-synchronous satellite GCOM-W1 was launched on 18 May 2012 by JAXA. GCOM-W1 is the first of three planned satellites of the GCOM-W project, which is a 13-year mission designed for global and continuous observation of Earth's water and energy cycles. AMSR2 has most of the characteristics of AMSR-E [31]. Both sensors are conical scanning passive microwave radiometers with similar instrument configurations. The AMSR instruments measure microwave emissions from the Earth surface twice daily for descending/ascending orbital equatorial crossings at 1:30 AM/PM local time, with vertically $(\mathrm{V})$ and horizontally $(\mathrm{H})$ polarized $T_{b}$ retrievals at six frequencies $(6.9,10.7,18.7,23.8,36.5,89.0 \mathrm{GHz})$. Major changes in AMSR2, distinctive from AMSR-E, include an additional frequency at $7.3 \mathrm{GHz}$ designed for mitigating Radio Frequency Interference (RFI), and a larger (2.0 m diameter) main reflector for enhanced spatial resolution. The MWRI onboard the FY-3B satellite was launched 5 November 2010. Similar to the channel setting and view geometry of AMSR-E, MWRI conically scans the Earth at five frequencies $(10.7,18.7,23.8,36.5$, 89.0 GHz) and dual $(\mathrm{H}, \mathrm{V})$ polarizations. The MWRI has four major differences from the AMSR instruments, including: (a) no C-band channel relative to the AMSR $10.7 \mathrm{GHz}$ channels due to widespread C-band RFI; (b) coarser spatial resolution and slightly narrower orbital swath for all frequencies relative to the AMSR sensors; (c) an approximate 10-min satellite overpass time difference between MWRI and AMSR-E; and (d) an approximate 53 degree earth incident angle (EIA) of measurement instead of 55 degrees for the AMSR sensors. Detailed sensor configurations for AMSR-E, AMSR2 and MWRI are summarized in Table 1.

Table 1. Satellite microwave sensor configurations used in this study.

\begin{tabular}{cccc}
\hline \multicolumn{4}{c}{ Instrument Configurations } \\
\hline Specifications & AMSR-2 & AMSR-E & MWRI \\
\hline Satellite Platform & GCOM-W1 & AQUA & FY3B \\
Altitude & $700 \mathrm{~km}$ & $705 \mathrm{~km}$ & $836 \mathrm{~km}$ \\
Equator Crossing Time & $1: 30$ p.m. Ascending & $1: 30$ p.m. Ascending & $1: 40$ p.m. Ascending \\
(Local time zone) & $1: 30$ a.m. Descending & $1: 30$ a.m. Descending & $1: 40$ a.m. Descending \\
Antenna Size & 2 m (Diameter) & 1.6 m (Diameter) & $0.977 \mathrm{~m} \times 0.897 \mathrm{~m}$ \\
Incident Angle & 55 & 55 & 53 \\
\hline \multicolumn{5}{c}{ Spatial Resolution $\mathbf{( k m} \times \mathbf{~ k m})$} & MWRI \\
\hline Band $\mathbf{( G H z )}$ & AMSR-2 & AMSR-E & N/A \\
\hline 6.93 & $62 \times 35$ & $75 \times 43$ & $85 \times 51$ \\
7.3 & $62 \times 35$ & N/A & $50 \times 30$ \\
10.65 & $42 \times 24$ & $51 \times 29$ & $45 \times 27$ \\
18.7 & $22 \times 14$ & $27 \times 16$ & $30 \times 18$ \\
23.8 & $19 \times 11$ & $32 \times 18$ & $15 \times 9$ \\
\hline 6.5 & $12 \times 7$ & $14 \times 8$ & $6 \times 4$ \\
\hline
\end{tabular}




\subsection{Ancillary Datasets and Study Sites}

Four ancillary datasets were employed for calibrating the AMSR2 $T_{b}$ record to the AMSR-E baseline. The datasets used for calibration include: (a) AMSR-E L2A Version 3 (V003) re-sampled swath $T_{b}$ data, which is the most recent version with complete recalibration to the Remote Sensing Systems (RSS) Version 7 standard; (b) AMSR2 L1R re-sampled swath $T_{b}$ records (version 1.1); (c) the MWRI Level 1 swath $T_{b}$ record; (d) daily minimum and maximum air temperature ( $T_{m n}$ and $T_{m x}$ ) measurements from global WMO weather stations that were used for independent validation of AMSR daily air temperature estimates derived from the calibrated $T_{b}$ results.

All of the satellite ascending and descending orbital swath $T_{b}$ data were spatially re-sampled and re-projected to a consistent 25-km resolution global Equal Area Scalable Earth (EASE) Grid (version 1) following previously established methods [32,33]. Based on the gridded data, four-month daily $T_{b}$ records of spatially and temporally collocated observations for MWRI and AMSR-E (1 June 2011 to 30 September 2011), and MWRI and AMSR2 (1 June 2013 to 30 September 2013) were extracted over all global land areas. The two sets of matched datasets were then used to evaluate sensor $T_{b}$ differences and develop pixel-wise empirical relationships for developing a consistent calibrated AMSR $T_{b}$ record. For the sensor inter-calibration evaluation, collocated $T_{b}$ observations of the three sensors involving both calibrated and uncalibrated results were extracted over five selected relatively homogeneous test regions, each approximately $1^{\circ} \times 1^{\circ}$ in size, and representing the major Köppen-Geiger global climate classification zones (Polar, Continental, Tropical, Dry, and Temperate Climate types). Among the regions, the Tropical test area in Amazonia (Latitude: $-6.35^{\circ}$ to $-7.14^{\circ}$, Longitude: $-64.82^{\circ}$ to $-65.85^{\circ}$ ) was previously used for inter-sensor comparisons between AMSR-E and WindSat [34]. The $T_{b}$ calibration was also assessed within major global land cover areas defined from a 0.05 degree resolution MODIS (MCD12C1) IGBP (International Geosphere-Biosphere Programme) land cover classification [35].

Surface $(\sim 2 \mathrm{~m}$ height) air temperature estimates were also derived from both calibrated and uncalibrated $T_{b}$ AM and PM orbital crossings over a three-year composited sensor record. The daily temperatures were derived for all global land areas using multi-frequency, ascending and descending orbit $T_{b}$ inputs from the composited sensor record and temperature estimation algorithms previously developed for AMSR-E [7]. The resulting air temperatures determined from the AMSR-E baseline and calibrated AMSR2 $T_{b}$ inputs were then compared with coincident in-situ daily air temperature measurements from 142 globally distributed WMO weather stations. Daily air temperatures determined from descending ( 1:30 a.m.) and ascending ( 1:30 p.m.) orbit AMSR $T_{b}$ inputs were compared against collocated $T_{m n}$ and $T_{m x}$ station measurements based on the assumption that the satellite overpasses are approximately coincident with the respective diurnal temperature minima and maxima. These comparisons were used for evaluating potential differences in temperature estimation accuracy between the AMSR-E baseline and calibrated AMSR2 records, and as a relative quality assessment of the AMSR2 $T_{b}$ calibration.

The composited three-year daily $T_{b}$ record used for air temperature estimation was derived from one-year of AMSR-E data (1 September 2010-31 August 2011), one-year of calibrated AMSR2 data (1 September 2012-31 August 2013) and one-year of calibrated MWRI data (1 September 2011-31 August 2012). Both the MWRI and AMSR2 $T_{b}$ records were calibrated to the AMSR-E baseline using 
the pixel-wise DD approach and collocated MWRI and AMSR $T_{b}$ observations for all global land areas. The WMO air temperature datasets supporting the three-year comparisons were obtained from the National Climate Data Center (NCDC) Global Summary of the Day (GSOD version 7). Similar to previous work [7], the WMO validation stations were selected within major global land cover classes determined from the MODIS IGBP land cover classification [35], while the number of WMO stations selected within each land cover class was proportional to its global land area representation. The locations of the 142 global WMO temperature validation sites and the five $T_{b}$ calibration test regions representing the major global climate zones are presented in Figure 1 and the corresponding inset map, respectively.

Figure 1. Global distribution of the WMO weather stations (white circles) used for validating the satellite surface air temperature estimates; the validation sites represent the global range of climate and land cover conditions represented by the MODIS IGBP global land cover map; The locations of five homogeneous test regions representing the major climate zones are represented by black squares and labeled as P, C, TR, D and T for Polar, Continental, Tropical, Dry, and Temperate Climate types, respectively. These test regions were used for partial validation of the sensor $T_{b}$ inter-calibration.

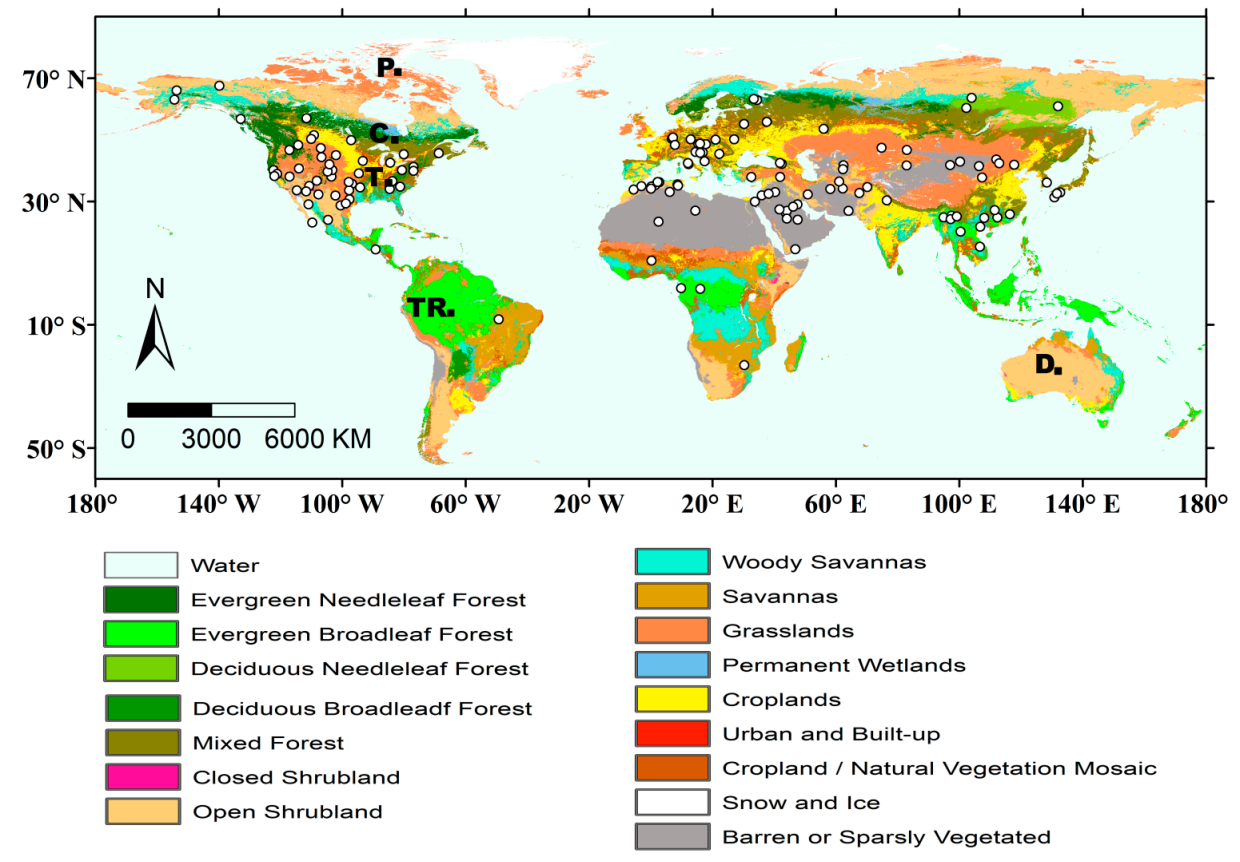

3. Methods

\subsection{Double Differencing Method}

As introduced in Section 1, Double Differencing (DD) is a straightforward and effective method for sensor inter-comparison and inter-calibration. By utilizing a third instrument as an intermediate reference, the DD method makes direct comparisons between target and reference sensors while avoiding potential uncertainty introduced by using a RTM, and mitigating negative impacts from systematic inconsistencies between the intermediate reference and inter-calibrated sensor records. The mathematical form of DD approach used in this study is expressed as: 


$$
\begin{aligned}
& D D(A M S R 2, A M S R-E)=S D(A M S R 2, M W R I)-S D(A M S R-E, M W R I) \\
& S D(A M S R 2, M W R I)=T_{b_{-} A M S R 2}-T_{b_{-} M W R I} \\
& S D(A M S R-E, M W R I)=T_{b_{-} A M S R-E}-T_{b_{-} M W R I}
\end{aligned}
$$

where SD (Kelvin) represents the single difference of the collocated sensor $T_{b}$ observations for a similar orbital retrieval, frequency and polarization. In this study, Equation (1) was applied for the two four-month matched sensor $T_{b}$ datasets with calculations made on a per pixel basis for each channel except $C$-band, which was not part of the MWRI sensor design. According to the available literature, comparisons between the MWRI, AMSR-E and SSMIS sensors indicate relatively stable and accurate MWRI $T_{b}$ measurements with calibration error of approximately $\pm 1.5 \mathrm{~K}$ for all frequencies [36]. These favorable MWRI characteristics and similar collocated observations spanning the AMSR sensor records enable the observation bias of AMSR2 in comparison to AMSR-E to be estimated from Equation (1). However, despite general similarities between these sensors, there are four major differences between MWRI and AMSR sensors as described in Section 2. In particular, the MWRI has coarser sampling footprints for all channel frequencies and an approximate 10-min difference in sensor acquisition overpass time from the AMSR sensors. This implies that the MWRI observations may not be fully consistent with the AMSR observations, especially for complex terrain and heterogeneous landscapes. Therefore, correlations between the MWRI and AMSR $T_{b}$ observations were first computed on a per grid cell basis over all global land areas. The subsequent estimation of DD values in Equation (1) were only determined for highly correlated pixels with $T_{b}$ correlations $(R)$ greater than 0.95 ( $p$-value $<0.05$ ).

\subsection{Inter-Calibration of AMSR2 and AMSR-E}

After describing observation biases between AMSR-E and AMSR2 using the above DD method, we then employed a linear calibration adjustment of the AMSR2 observations against the AMSR-E baseline. The linear relationships between collocated MWRI and AMSR $T_{b}$ observations for the well-correlated pixels were described as:

$$
\begin{aligned}
& T_{b_{-} A M S R-E}=a_{1}+b_{1} \cdot T_{b_{-} M W R I} \\
& T_{b_{-} A M S R-2}=a_{2}+b_{2} \cdot T_{b_{-} M W R I}
\end{aligned}
$$

where $a_{1}, b_{1}, a_{2}, b_{2}$ are empirical regression coefficients derived from the matched datasets for each pixel. Therefore,

$$
T_{b_{-} A M S R-E}=a+b \cdot T_{b_{-} A M S R 2}
$$

where $a=a_{1}-a_{2} \cdot b_{1} / b_{2}$ and $b=b_{1} / b_{2}$.

For pixels where the $T_{b}$ observations between AMSR and MWRI were well correlated $(R>0.95)$, coefficients, $a$ and $b$, were calculated directly based on the pixel-wise linear regression results; otherwise an Inverse Distance Weighting (IDW) method was used for spatial interpolation estimation of $a$ and $b$ from nearby pixels having the same land cover type and successfully calculated parameter ( $a$ and $b$ ) values. The pixel-wise regression and IDW method are intended to account for possible spatial variations of sensor biases, which are illustrated in the following Subsection 4.1. 


\subsection{Air Temperature Estimation Method}

Surface air temperature is an essential climate variable for determining the state of the climate system and monitoring environmental change. It also plays a critical role in regulating environmental processes and land-atmosphere interactions governing surface water, energy and carbon budgets [37,38]. In [7], $T_{m n}$ and $T_{m x}$ over the Northern Hemisphere were estimated based on an iterative method using multi-frequency $T_{b}$ records from AMSR-E. After screening out potential precipitation, Radio Frequency Interference (RFI), snow and frozen conditions based on the procedure by [7], three $T_{b}$ ratios from the AMSR-E 18.7 and $23.8 \mathrm{GHz}$ channels are first employed iteratively to determine the optical thickness of atmospheric water vapor, land surface open water fraction and vegetation transmissivity. This information is then used to solve for the effective surface temperature, $T_{s}$, which was found to be well correlated with surface air temperature. By comparing with daily measurements from WMO weather stations, the resulting $T_{s}$ retrievals for respective morning (AM) and afternoon (PM) overpasses were empirically related to $T_{m n}$ and $T_{m x}$ in the similar empirical regression form as Equations (5) and (6). The algorithm was developed for the Version 2 AMSR-E/Aqua L2A dataset and showed favorable accuracy $\left(R^{2} \geq 0.79, R M S E=3.5 \mathrm{~K}\right)$ against daily temperature measurements from independent weather stations representing a broad range of climate and land cover conditions [7].

In this study, we applied the same algorithm as [7] but with regression coefficients adjusted to reflect reprocessing updates of the AMSR-E $T_{b}$ record from Remote Sensing Systems (RSS) Version 6 to Version 7 as:

$$
\begin{gathered}
T_{m n}=2.05+0.89 T_{s}+1.83 T_{c}-4.47 T_{c}^{2}-0.10(\text { abs }(\text { Lat })) \\
T_{m x}=6.21+0.86 T_{s}-19.71 T_{c}+23.15 T_{c}^{2}-0.10(\text { abs }(\text { Lat }))
\end{gathered}
$$

where $T_{m n}$ and $T_{m x}$ (Celsius) are the respective daily minimum and maximum surface air temperature estimation of the satellite morning and afternoon overpasses; $T_{c}$ is the dimensionless frequency dependent vegetation transmissivity; $T_{s}$ is the effective surface temperature in Celsius, and Lat is the geographic latitude of the temperature estimation.

\section{Results and Discussion}

\subsection{Inter-Calibration between AMSR2, AMSR-E and MWRI}

Stable and well-correlated $T_{b}$ observations from AMSR-E, AMSR2 and MWRI form the basis of the sensor inter-calibrations. The channel specific $T_{b}$ correlations between the AMSR and MWRI sensors were thus examined first for the two, four-month overlapping data records. The linear correlation coefficient $R$ was calculated from the overlapping sensor records for each $25 \mathrm{~km}$ resolution pixel within the global land domain, while the mean $T_{b}$ sample size used to determine $R$ for each pixel was $50.4 \pm 29.6$ days for the AMSR-E and MWRI overlapping data record and 49.2 \pm 29.5 days for the AMSR2 and MWRI overlapping record. Generally favorable $T_{b}$ correlations were observed over the global domain from the overlapping MWRI and AMSR records for all analyzed frequencies, orbits and polarizations, though the locations and global extent of significant correlations varied according to the different channel frequencies (e.g., Tables 2 and 3). As an illustrated example, correlation maps of 
collocated H-Polarized $T_{b}$ ascending observations for the intermediate $23 \mathrm{GHz}$ channel from the overlapping MWRI and AMSR records are presented in Figure 2. The global patterns of $23 \mathrm{GHz}$ results are similar to the other frequency results, while the $23 \mathrm{GHz}$ channel is also important for the subsequent air temperature estimation. More detailed summaries representing all frequencies are listed in Tables 2 and 3. The $23 \mathrm{GHz}$ results from the MWRI and AMSR sensor records are highly correlated $(R>0.95)$ over more than half of the global domain. Regions with lower $T_{b}$ correlations $(R<0.85)$ were located near large water bodies, including coastal areas, the Great Lakes and Amazon River. This is expected due to the variable spatial sampling and coverage of the collocated elliptical sensor footprints, which reflect satellite orbital differences and discrepancies in sensor spatial resolutions and geolocation accuracy. In particular, the inclusion of different fractional water coverage in the collocated footprints can lead to significant differences in the $T_{b}$ observations due to the large dielectric contrast between water and land features. To minimize the effect of these uncertainties on the sensor $T_{b}$ inter-comparison and calibration, only highly correlated pixels $(R>0.95)$ were selected for further evaluation of sensor observation biases. The overall $T_{b}$ bias of MWRI against AMSR2 or AMSR-E was directly calculated by the SD method while the bias of AMSR2 against AMSR-E was indirectly estimated by the DD method using Equation (1). The resulting global distribution of estimated AMSR2 bias in relation to the baseline AMSR-E record is illustrated in Figure 3a,b for respective $23 \mathrm{GHz}$ and $18 \mathrm{GHz}$, H-Polarized ascending $T_{b}$ records. The AMSR 2 ascending $T_{b}$ record at $23 \mathrm{GHz}$ and $18 \mathrm{GHz}$ is approximately $2.10 \mathrm{~K}$ and $2.46 \mathrm{~K}$ higher than the AMSR-E record over the global domain. Higher $T_{b}$ bias was generally found in regions of colder radiance, such as the Polar regions and Sahara Desert, where lower $T_{b}$ observations are caused by low surface temperature and/or low H-pol emissivity. This finding is consistent with the previous study from JAXA that showed much larger AMSR2 biases toward the cold end of the $T_{b}$ range $[28,29]$.

Table 2. Summary of sensor ascending orbit $T_{b}$ mean biases (Unit: Kelvin) and Standard Deviation (STD) (Unit: Kelvin) values estimated from overlapping AMSR and MWRI records for well correlated $(R>0.95)$ pixels, and the percentage of the global land domain with $R>0.95$.

\begin{tabular}{ccccccc}
\hline \multirow{2}{*}{ Pairwise Comparisons } & \multicolumn{3}{c}{ H_Pol } & \multicolumn{3}{c}{ V_Pol } \\
\cline { 2 - 7 } & Bias & STD & Percentage & Bias & STD & Percentage \\
\hline & \multicolumn{7}{c}{$10 \mathrm{GHz}$} \\
\hline MWRI-AMSR-E & -2.78 & 2.09 & 42.86 & -3.13 & 1.29 & 59.46 \\
MWRI-AMSR2 & -5.85 & 2.22 & 40.51 & -4.61 & 1.59 & 56.43 \\
\hline & \multicolumn{7}{c}{$18 \mathrm{GHz}$} \\
\hline MWRI-AMSR-E & -0.34 & 1.68 & 47.22 & 0.20 & 1.12 & 61.18 \\
MWRI-AMSR2 & -2.80 & 1.54 & 49.50 & -1.35 & 1.34 & 61.79 \\
\hline & \multicolumn{7}{c}{$23 \mathrm{GHz}$} \\
\hline MWRI-AMSR-E & -2.58 & 1.34 & 60.83 & -2.36 & 0.98 & 66.01 \\
MWRI-AMSR2 & -4.67 & 1.03 & 65.21 & -3.75 & 0.94 & 69.28 \\
\hline & \multicolumn{7}{c}{$36 \mathrm{GHz}$} \\
\hline MWRI-AMSR-E & -3.06 & 1.69 & 49.07 & -4.01 & 1.18 & 60.06 \\
MWRI-AMSR2 & -4.39 & 1.29 & 54.96 & -4.83 & 0.98 & 63.20 \\
\hline & & \multicolumn{7}{c}{$89 \mathrm{GHz}$} \\
\hline MWRI-AMSR-E & -1.83 & 1.66 & 27.24 & -1.66 & 1.06 & 32.95 \\
MWRI-AMSR2 & -1.98 & 1.54 & 28.94 & -2.33 & 1.03 & 36.15 \\
\hline
\end{tabular}


Table 3. Summary of sensor Descending orbit $T_{b}$ mean biases (Unit: Kelvin) and Standard Deviation (STD) (Unit: Kelvin) values estimated from overlapping AMSR and MWRI records for well correlated $(R>0.95)$ pixels, and the percentage of the global land domain with $R>0.95$.

\begin{tabular}{|c|c|c|c|c|c|c|}
\hline \multirow{2}{*}{ Pairwise Comparisons } & \multicolumn{3}{|c|}{ H_Pol } & \multicolumn{3}{|c|}{ V_Pol } \\
\hline & Bias & STD & Percentage & Bias & STD & Percentage \\
\hline \multicolumn{7}{|c|}{$10 \mathrm{GHz}$} \\
\hline MWRI-AMSR-E & -1.39 & 2.53 & 36.10 & -2.23 & 1.52 & 52.46 \\
\hline MWRI-AMSR2 & -4.04 & 2.73 & 33.95 & -4.34 & 1.67 & 48.92 \\
\hline \multicolumn{7}{|c|}{$18 \mathrm{GHz}$} \\
\hline MWRI-AMSR-E & 0.84 & 2.25 & 41.76 & 1.07 & 1.43 & 54.68 \\
\hline MWRI-AMSR2 & -0.93 & 2.21 & 41.12 & -1.07 & 1.52 & 53.26 \\
\hline \multicolumn{7}{|c|}{$23 \mathrm{GHz}$} \\
\hline MWRI-AMSR-E & -1.16 & 2.29 & 60.21 & -1.52 & 1.56 & 61.53 \\
\hline MWRI-AMSR2 & -3.00 & 1.97 & 60.30 & -3.19 & 1.40 & 60.62 \\
\hline \multicolumn{7}{|c|}{$36 \mathrm{GHz}$} \\
\hline MWRI-AMSR-E & -1.41 & 2.28 & 47.22 & -2.84 & 1.37 & 56.53 \\
\hline MWRI-AMSR2 & -3.00 & 1.81 & 50.56 & -3.94 & 1.30 & 57.71 \\
\hline \multicolumn{7}{|c|}{$89 \mathrm{GHz}$} \\
\hline MWRI-AMSR-E & -0.20 & 1.62 & 34.20 & -0.39 & 1.14 & 34.42 \\
\hline MWRI-AMSR2 & -0.84 & 1.85 & 34.57 & -1.27 & 1.44 & 36.96 \\
\hline
\end{tabular}

Figure 2. Spatial distribution of the correlation coefficients calculated from four-month overlapping (a) AMSR-E and MWRI and (b) AMSR2 and MWRI datasets for selected $23 \mathrm{GHz}, \mathrm{H}-\mathrm{Polarized}$ ascending orbit $T_{b}$ observations; lower correlation areas are associated with coastal boundaries having large dielectric differences between land and open water features, and other heterogeneous land areas.

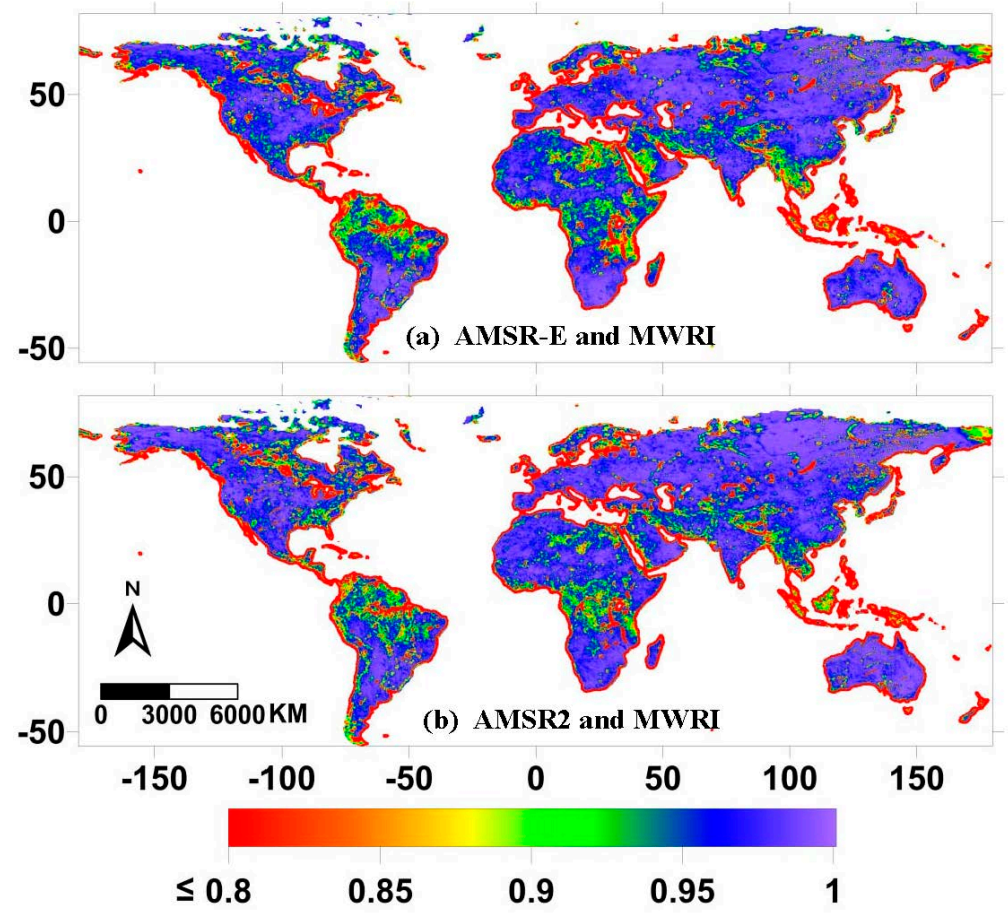


Figure 3. Example global distributions of estimated ascending orbit $T_{b}$ biases between uncalibrated AMSR2 and AMSR-E baseline observations for the H-Polarized (a) $23 \mathrm{GHz}$, and (b) $18 \mathrm{GHz}$ channels, respectively (areas with correlation coefficient $R<0.95$ are marked in grey).

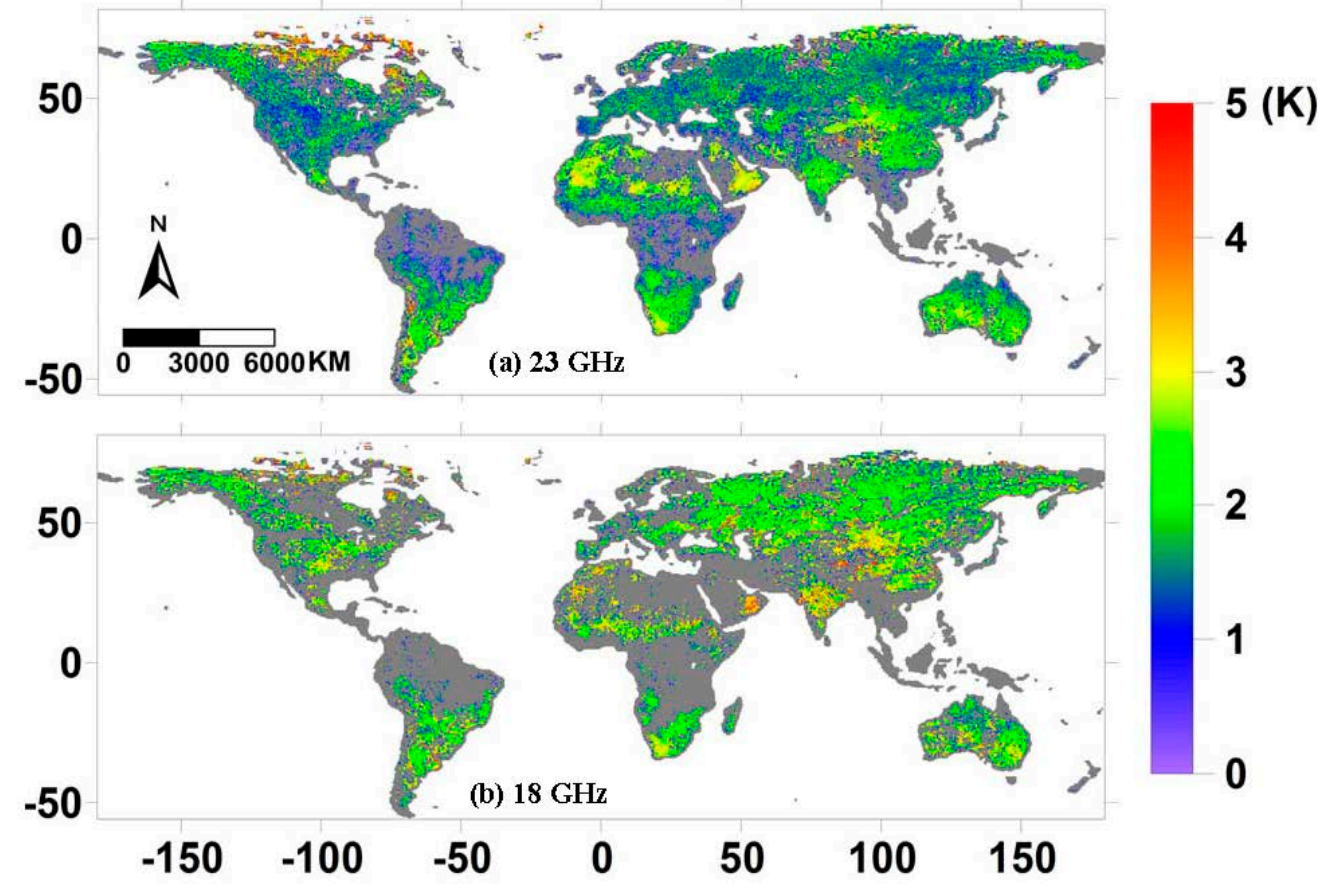

The complete $T_{b}$ inter-comparison results for the three sensor records and all matching frequencies are summarized in Table 2 for ascending orbits and Table 3 for descending orbits. The statistical metrics for the overlapping data records include the mean $T_{b}$ difference or bias, the standard deviation (STD) of the $T_{b}$ difference and the percentage of the global land area with $R>0.95$. By referring to AMSR-E as the standard or baseline, it can be seen from Tables 2 and 3 that AMSR2 tends to generate higher $T_{b}$ readings for all channels, while MWRI generally produces lower $T_{b}$ values. Meanwhile, MWRI and AMSR observations are highly correlated $(R>0.95)$ over approximately $27 \%-69 \%$ of the global land area, depending on $T_{b}$ frequency and polarization. As discussed in the previous paragraph, variable spatial sampling and coverage of the collocated elliptical sensor footprints may lead to low correlation of the observations. The cross-sensor $T_{b}$ correlation is also lowest for the $89 \mathrm{GHz}$ channel as indicated from Tables 2 and 3. As introduced in Subsection 2.1, there is an approximate 10-min overpass time difference between AMSR and MWRI and changing atmosphere conditions may lead to a lower correlation. The calibration correction of AMSR2 $T_{b}$ to the AMSR-E baseline was conducted individually for each channel frequency, polarization and orbit. Based on Tables 2 and 3, global mean biases between AMSR2 and AMSR-E observations can be estimated for each sensor channel. As is seen in Figure 4, the AMSR2 observations are systematically deviated from the AMSR-E baseline by approximately $0.15 \mathrm{~K}-3.06 \mathrm{~K}$, depending on the $T_{b}$ frequency, polarization and ascending/descending orbits.

Based on the observed strong linear correlations between the sensor observations, empirical linear relationships were derived between the AMSR $T_{b}$ observations using Equations (2)-(4) to calibrate the AMSR2 record to the AMSR-E baseline. Based on the MWRI matched datasets, the intercept and slope of the relationship between AMSR2 and AMSR-E were directly calculated in Equations (2)-(4) 
for well correlated land pixels $(R>0.95)$, and spatially interpolated over the remaining land areas using the IDW method. The calculation was carried out for each channel on a per pixel basis. Example $T_{b}$ slope and intercept distribution maps describing relations between the AMSR2 and AMSR-E records is given in Figure 5 for the $23 \mathrm{GHz}, \mathrm{H}$-Polarized ascending $T_{b}$ observations. Assuming the relationships between the sensors are stable over the observation record, the empirical slope and intercept maps provide effective ancillary inputs for calibrating the AMSR2 and MWRI $T_{b}$ records to the AMSR-E baseline. Using this approach and the overlapping sensor $T_{b}$ observations, the available AMSR2 (July 2012-September 2013) and MWRI (June 2011-September 2013) records were linearly calibrated to the AMSR-E (June 2002-October 2011) $T_{b}$ record. The resulting integrated $T_{b}$ observations from the three sensors spanned a continuous, calibrated daily observation record extending from June 2002-September 2013, and consistent with the AMSR-E baseline.

Figure 4. Global mean biases (Unit: Kelvin) between AMSR2 and AMSR-E estimated from overlapping AMSR and MWRI records for well correlated $(R>0.95)$ pixels for each frequency and polarization (blue line is for the ascending orbits and red line for descending orbits).

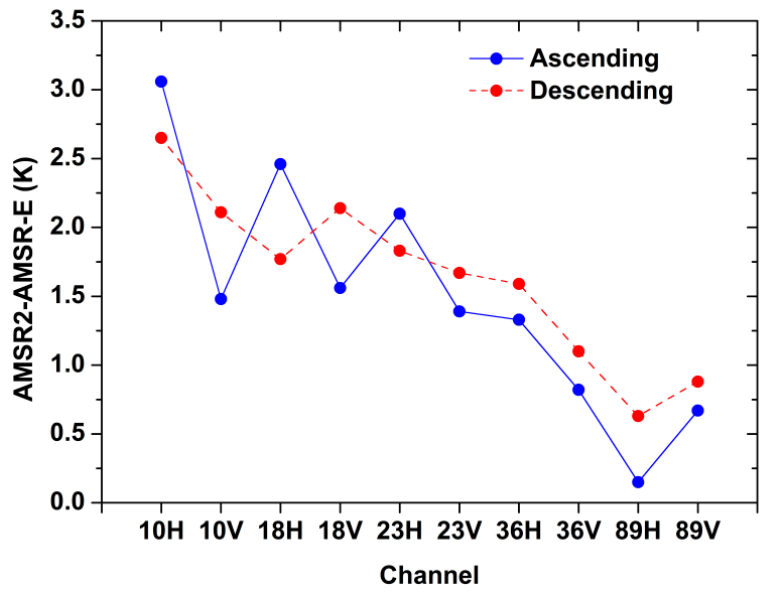

Figure 5. Example global distributions of the empirical (a) intercept and (b) slope values that define the linear relationship between AMSR2 $T_{b}$ observations (dependent variable) and the AMSR-E baseline (independent variable) for ascending H-Polarized observations at $23 \mathrm{GHz}$.

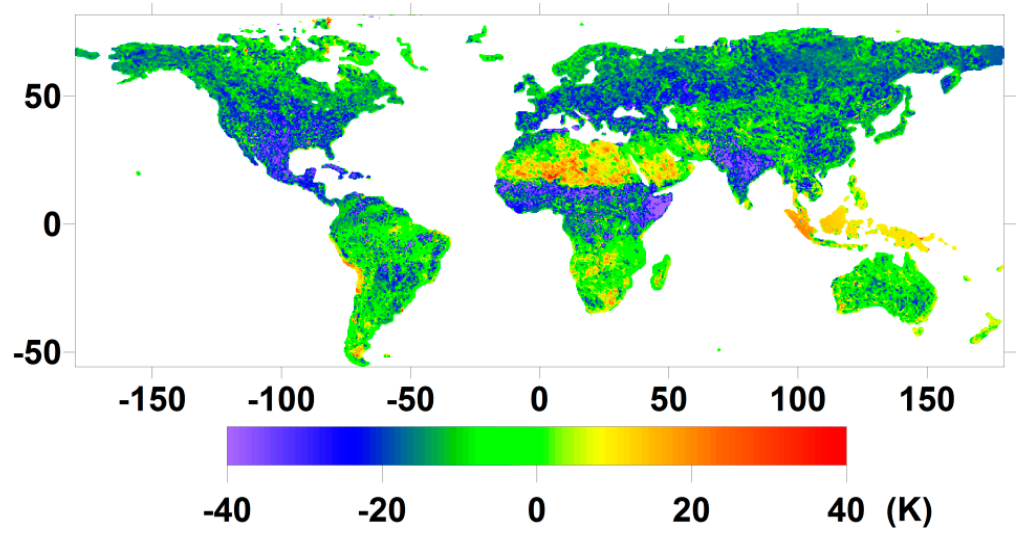

(a) 
Figure 5. Cont.

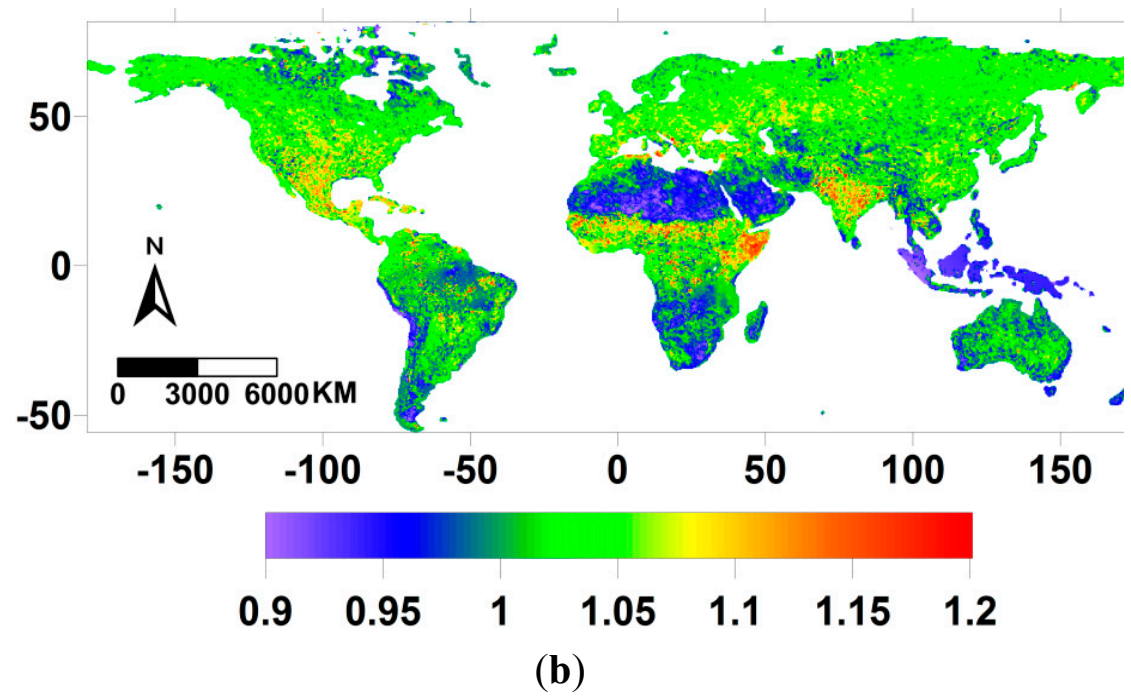

\subsection{Evaluation of the Sensor Inter-Calibration Results}

The performance of the sensor $T_{b}$ inter-calibration results was examined for five, homogeneous $1^{\circ} \times 1^{\circ} T_{b}$ calibration test regions representing major Köppen-Geiger global climate classification zones, including Polar, Continental, Tropical, Dry, and Temperate climate types (Figure 1). Spatial mean $T_{b}$ values were calculated for each test region. To ensure relatively homogenous conditions suitable for inter-calibration, the test regions were selected on the basis of having standard deviations of vertical polarization $T_{b}$ values not exceeding $2 \mathrm{~K}$, and standard deviations of horizontal polarization $T_{b}$ values not exceeding $3 \mathrm{~K}$ [39]. The $T_{b}$ calibration test results representing all frequencies and polarizations are summarized Tables 4 to 5 . These results indicate that the $T_{b}$ inter-calibration method significantly mitigates sensor observation biases for all channels over the broad range of global climate conditions represented by the five test regions.

Table 4. Summary of sensor ascending (PM) orbit $T_{b}$ mean biases (Unit: Kelvin), Root Mean Square Error (RMSE) differences and Correlation Coefficients across all frequencies and polarizations estimated from overlapping AMSR and MWRI records before and after $T_{b}$ calibration for five regions representing major Köppen-Geiger global climate classification zones.

\begin{tabular}{ccccccc}
\hline \multirow{2}{*}{ Climate Type } & \multicolumn{3}{c}{ Before Calibration } & \multicolumn{3}{c}{ After Calibration } \\
\cline { 2 - 7 } & Bias & RMSE & Correlation & Bias & RMSE & Correlation \\
\hline Polar & -4.01 & 4.65 & 0.96 & 0.19 & 1.11 & 0.99 \\
Continental & -3.88 & 4.08 & 0.97 & -0.18 & 0.97 & 0.98 \\
Tropical & -2.59 & 2.88 & 0.90 & 0.04 & 0.46 & 0.98 \\
Dry & -2.34 & 2.74 & 0.97 & -0.01 & 0.58 & 0.99 \\
Temperate & -3.00 & 3.18 & 0.97 & 0.05 & 0.58 & 0.99 \\
\hline
\end{tabular}


Table 5. Summary of sensor descending (AM) orbit $T_{b}$ mean biases (Unit: Kelvin), Root Mean Square Error (RMSE) differences and Correlation Coefficients across all frequencies and polarizations estimated from overlapping AMSR and MWRI records before and after $T_{b}$ calibration for five regions representing major Köppen-Geiger global climate classification zones.

\begin{tabular}{ccccccc}
\hline \multirow{2}{*}{ Climate Type } & \multicolumn{3}{c}{ Before Calibration } & \multicolumn{3}{c}{ After Calibration } \\
\cline { 2 - 7 } & Bias & RMSE & Correlation & Bias & RMSE & Correlation \\
\hline Polar & -3.05 & 3.92 & 0.94 & 0.03 & 1.12 & 0.98 \\
Continental & -2.51 & 2.83 & 0.97 & -0.04 & 0.63 & 0.99 \\
Tropical & -0.80 & 1.52 & 0.79 & -0.31 & 0.51 & 0.92 \\
Dry & -1.14 & 1.64 & 0.97 & -0.07 & 0.54 & 0.99 \\
Temperate & -2.01 & 2.33 & 0.96 & -0.06 & 0.47 & 0.99 \\
\hline
\end{tabular}

The selected tropical $T_{b}$ calibration test area in central Amazonia (Figure 1) was identified as relatively homogenous at microwave frequencies and suitable for sensor inter-comparisons from a previous study [34]. Both un-calibrated and calibrated AMSR2 and MWRI $T_{b}$ (H-Polarization, and Ascending orbit) values for the $23 \mathrm{GHz}, 18 \mathrm{GHz}$ and $10 \mathrm{GHz}$ channels are compared with collocated AMSR-E baseline observations for this region in Figure 6. For the $23 \mathrm{GHz}$ example, there are 59 point pairs evaluated in both Figure 6a,b. These results indicate that the AMSR-E and AMSR2 $T_{b}$ values (Y-axis) as a whole are well correlated with the MWRI data $(R=0.90)$ but also show large $T_{b}$ differences of approximately $-3.14 \mathrm{~K}$ (Bias) and $3.31 \mathrm{~K}(R M S E)$. The resulting empirical calibration of AMSR2 and MWRI observations to the AMSR-E baseline described in Section 3 produced generally consistent $T_{b}$ observations across the three sensor records (Figure 6b). The resulting calibrated AMSR2 and MWRI $T_{b}$ values for the reference area correspond favorably with the AMSR-E baseline $(R=0.99$, $R M S E=0.42 \mathrm{~K}$, Bias $=0.04 \mathrm{~K}$ ), and are consistent with the inter-calibration results from the other climate test regions. Similarly, instrument biases were corrected for the other frequencies. As illustrated in Figure 6c-f, $R$ increased from $0.82-0.98$ for $18 \mathrm{GHz}$ and $0.76-0.98$ for $10 \mathrm{GHz}$, respectively; bias also decreased from $-0.45 \mathrm{~K}$ to $-0.10 \mathrm{~K}$ for $18 \mathrm{GHz}$ and $-3.60 \mathrm{~K}$ to $0.24 \mathrm{~K}$ for $10 \mathrm{GHz}$, respectively. Note that $T_{b}$ observations from AMSR sensors are generally higher than the uncalibrated MWRI observations except for $18 \mathrm{GHz}$ channels where slightly lower AMSR-E $T_{b}$ values were found as shown in Figure 6c and also Tables 2 and 3.

The global $T_{b}$ calibration results were also summarized for the major global land cover classes according to $T_{b}$ ascending (Table 6) and descending (Table 7) orbits. The statistical parameters presented include the mean bias, RMSE and correlation coefficient which are averaged for all channels for the uncalibrated and calibrated results within each land cover class. Similar to climate based $T_{b}$ calibration test, the land cover assessment results also indicate that the inter-calibration process mitigated most observation biases. Further analysis of residual errors from the resulting calibration showed no apparent non-linear bias or other artifacts in the integrated $T_{b}$ record. However, the RMSE differences were only partially reduced and the correlations between datasets were slightly improved. The $T_{b}$ differences from AMSR and MWRI are not only caused by different instrument calibrations, but also by other factors including different sensor spatial coverage, temporal sampling and random uncertainty in the observations. With observation biases mitigated, the calibrated AMSR2 and MWRI $T_{b}$ values 
are similar to the AMSR-E baseline, though further integration refinement of the sensor records would likely benefit by more explicit accounting of the different sensor spatial and temporal characteristics.

Figure 6. H-Polarized $T_{b}$ comparisons from overlapping MWRI and AMSR ascending orbit observations for the selected Amazon tropical reference area; the comparisons represent both (left panel) original uncalibrated and (right panel) calibrated (a,b) $23 \mathrm{GHz}$ (c,d) $18 \mathrm{GHz}$ $(\mathbf{e}, \mathbf{f}) 10 \mathrm{GHz}$ MWRI and AMSR2 $T_{b}$ results relative to the AMSR-E baseline for $23 \mathrm{GHz}$, $18 \mathrm{GHz}$ and $10 \mathrm{GHz}$ channels.

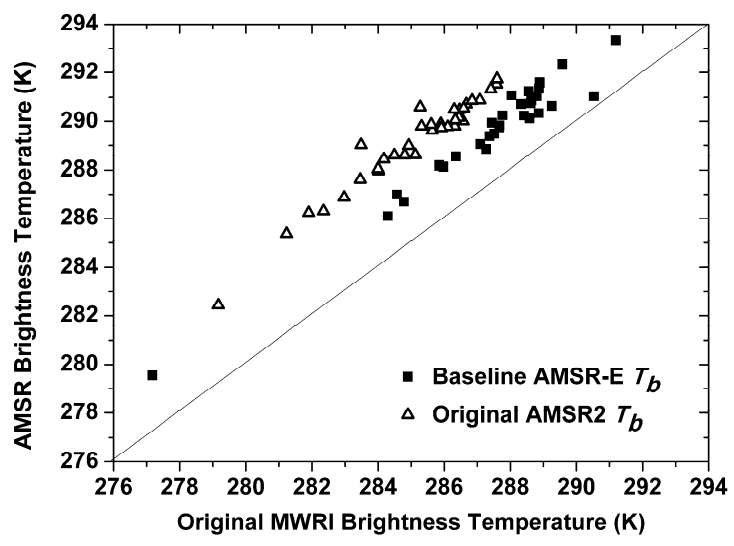

(a)

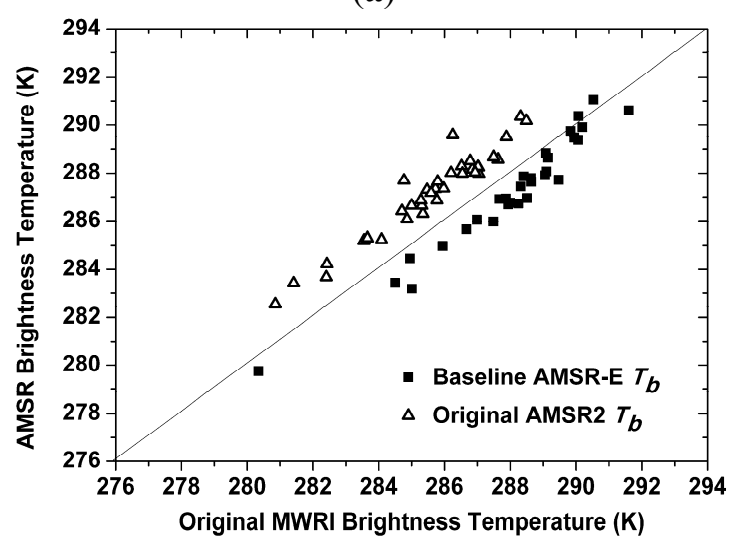

(c)

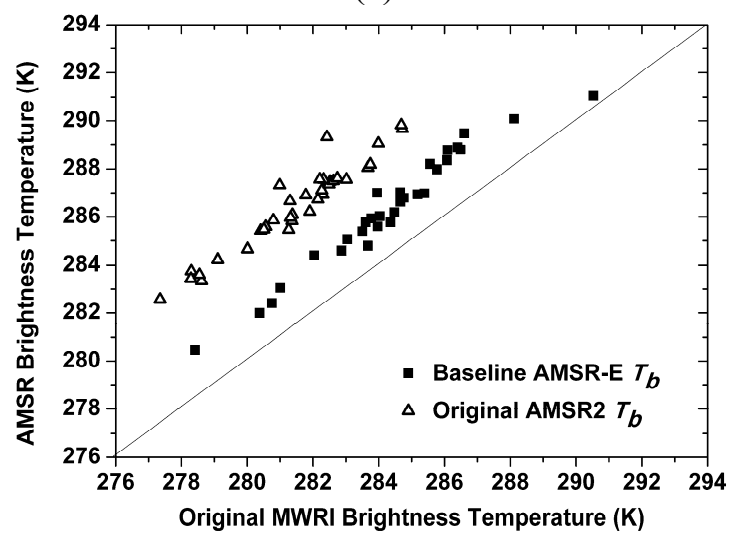

(e)

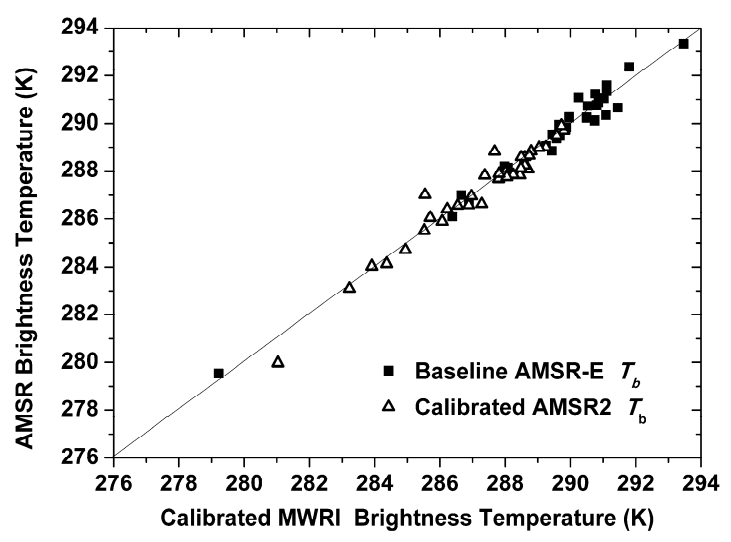

(b)

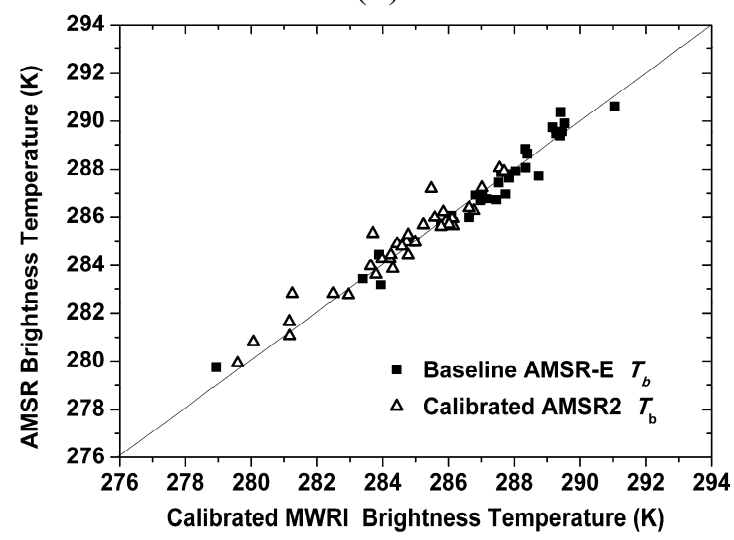

(d)

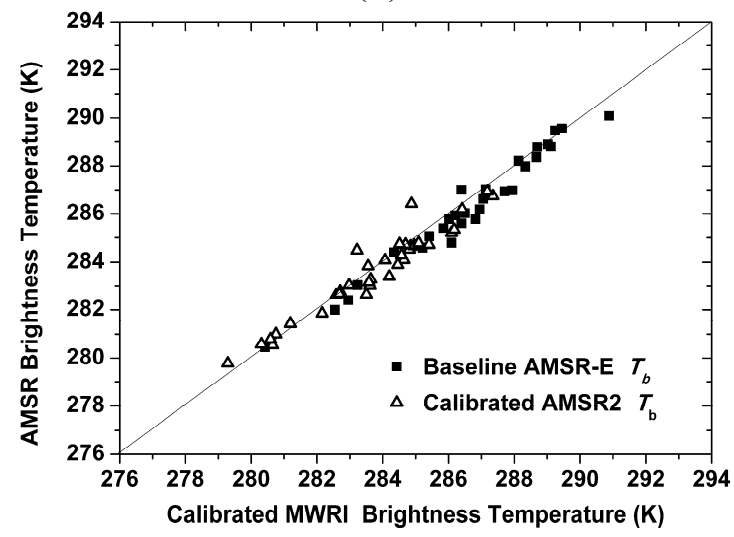

(f) 
Table 6. Summary of sensor ascending (PM) orbit $T_{b}$ mean biases (Unit: Kelvin), Root Mean Square Error (RMSE) differences and Correlation Coefficients across all frequencies and polarizations estimated from overlapping AMSR and MWRI records before and after $T_{b}$ calibration for major IGBP land cover type areas within the global domain.

\begin{tabular}{ccccccc}
\hline \multirow{2}{*}{ Land Cover Type } & \multicolumn{3}{c}{ Before Calibration } & \multicolumn{3}{c}{ After Calibration } \\
\cline { 2 - 7 } & Bias & RMSE & Correlation & Bias & RMSE & Correlation \\
\hline ENF * & -3.93 & 5.60 & 0.85 & -0.49 & 3.51 & 0.87 \\
EBF * & -3.13 & 5.45 & 0.70 & -0.02 & 3.86 & 0.78 \\
DNF * & -3.21 & 4.30 & 0.94 & -0.04 & 2.18 & 0.95 \\
DBF * & -3.23 & 4.59 & 0.89 & -0.08 & 2.55 & 0.90 \\
Mixed Forest & -3.31 & 5.36 & 0.85 & 0.09 & 3.40 & 0.87 \\
Shrublands * & -3.24 & 4.81 & 0.89 & -0.15 & 2.84 & 0.91 \\
Woody Savannas & -3.07 & 4.53 & 0.84 & -0.18 & 2.60 & 0.88 \\
Savannas & -2.46 & 4.08 & 0.85 & 0.11 & 2.39 & 0.89 \\
Grasslands & -2.82 & 4.29 & 0.92 & -0.01 & 2.50 & 0.93 \\
Croplands & -3.21 & 5.33 & 0.87 & 0.03 & 3.45 & 0.88 \\
Cropland/Natural Vegetation Mosaic & -3.02 & 4.82 & 0.86 & 0.08 & 3.04 & 0.88 \\
Barren or Sparsely Vegetated & -2.47 & 4.08 & 0.83 & -0.26 & 2.48 & 0.88 \\
\hline
\end{tabular}

* ENF for Evergreen Needleleaf Forest, EBF for Evergreen Broadleaf Forest, DNF for Deciduous Needleleaf Forest; DBF for Deciduous Broadleaf Forest; Shrublands include both Closed Shrubland and Open Shrubland.

Table 7. Summary of sensor descending (AM) orbit $T_{b}$ mean biases (Unit: Kelvin), Root Mean Square Error (RMSE) differences and Correlation Coefficients estimated from overlapping AMSR and MWRI records before and after $T_{b}$ calibration for major IGBP land cover type areas within the global domain.

\begin{tabular}{ccccccc}
\hline \multirow{2}{*}{ Land Cover Type } & \multicolumn{3}{c}{ Before Calibration } & \multicolumn{3}{c}{ After Calibration } \\
\cline { 2 - 7 } & Bias & RMSE & Correlation & Bias & RMSE & Correlation \\
\hline ENF * & -2.92 & 4.74 & 0.84 & -0.30 & 3.12 & 0.88 \\
EBF * & -2.13 & 4.51 & 0.68 & -0.69 & 3.73 & 0.74 \\
DNF * & -2.69 & 3.87 & 0.92 & -0.14 & 2.00 & 0.94 \\
DBF * & -1.83 & 3.40 & 0.90 & -0.37 & 2.10 & 0.92 \\
Mixed Forest & -3.15 & 4.79 & 0.84 & -0.66 & 3.14 & 0.88 \\
Shrublands * & -2.19 & 3.94 & 0.88 & -0.29 & 2.54 & 0.91 \\
Woody Savannas & -1.57 & 3.48 & 0.79 & -0.34 & 2.46 & 0.84 \\
Savannas & -1.61 & 3.35 & 0.84 & -0.81 & 2.56 & 0.87 \\
Grasslands & -1.82 & 3.41 & 0.90 & -0.14 & 2.12 & 0.92 \\
Croplands & -2.48 & 4.52 & 0.86 & -0.56 & 3.28 & 0.88 \\
Cropland/Natural Vegetation Mosaic & -2.38 & 4.04 & 0.86 & -0.68 & 2.82 & 0.89 \\
Barren or Sparsely Vegetated & -1.38 & 3.59 & 0.83 & -0.10 & 2.43 & 0.88 \\
\hline
\end{tabular}

* ENF for Evergreen Needleleaf Forest, EBF for Evergreen Broadleaf Forest, DNF for Deciduous Needleleaf Forest; DBF for Deciduous Broadleaf Forest; Shrublands include both Closed Shrubland and Open Shrubland. 


\subsection{Air Temperature Estimation Results}

The global integrated sensor $T_{b}$ record was used as a daily ancillary input for estimating surface air temperatures using algorithms Equations (5) and (6) adapted from AMSR-E [7]. Daily $T_{m x}$ and $T_{m n}$ estimates were derived from respective ascending (PM) and descending (AM) orbit $T_{b}$ inputs and used for further assessment of the integrated sensor record. The resulting satellite temperature $\left(T_{m x}\right.$ and $\left.T_{m n}\right)$ estimates were validated against coincident in-situ air temperature measurements from 142 independent weather stations encompassing a broad range of global climate and land cover conditions. The air temperature estimates were extracted for three, one-year periods representing baseline AMSR-E and calibrated MWRI and AMSR2 portions of the integrated $T_{b}$ record used for the validation assessment.

As introduced in Section 3.3, the air temperature estimates directly depend on the $T_{b}$ observations at 18 and $23 \mathrm{GHz}$ channels; the temperature estimates also indirectly depend on other channels used to identify and screen out unfavorable retrieval conditions, including high fractional water inundation, active precipitation or frozen surface conditions [7]. Therefore, the air temperature estimation is sensitive to all $T_{b}$ channels ranging from 10-89 GHz. We assumed that the overall quality of the in-situ measurements from the $142 \mathrm{WMO}$ validation sites was consistent over the three sensor years, so that the resulting temperature validation reflects the quality and consistency of both the $T_{b}$ calibration and temperature estimation from the different sensors. The comparisons between measured and estimated $T_{m x}$ from the AMSR-E baseline and calibrated AMSR2 $T_{b}$ records are shown in Figure 7 for the 142 validation sites. The global temperature estimates from the AMSR-E baseline show generally good correlation $\left(R^{2}=0.86\right)$ and low error $\left(R M S E=3.37{ }^{\circ} \mathrm{C}\right)$ relative to the in situ station measurements (Figure 6a), and consistent with temperature validation results from a previous Northern Hemisphere study [7]. The temperature estimates from the calibrated AMSR2 $T_{b}$ record were also favorable $\left(R^{2}=0.83\right.$ and $\left.R M S E=3.64{ }^{\circ} \mathrm{C}\right)$ but represented a small, but significant $(p<0.05)$ accuracy reduction from the AMSR-E baseline. The overall statistical results of the temperature validation comparisons are summarized in Table 8. Overall, the AMSR temperature estimates are well correlated with the in-situ measurements and show favorable accuracy $\left(R^{2} \geq 0.75, R M S E \leq 3.64{ }^{\circ} \mathrm{C}\right)$. These results also indicate that the calibrated AMSR2 data record can be used for extending the AMSR-E land parameter record with reasonable accuracy and consistency. However, the calibrated MWRI $T_{b}$ record produced substantially lower temperature estimation accuracy relative to the station measurements (Table 8), with both lower temperature correspondence $\left(R^{2}=0.80\right.$ for $T_{m x}$ and $R^{2}=0.69$ for $\left.T_{m n}\right)$ and larger $R M S E\left(4.12{ }^{\circ} \mathrm{C}\right.$ for $T_{m x}$ and $4.11{ }^{\circ} \mathrm{C}$ for $\left.T_{m n}\right)$ differences than the AMSR results. The lower MWRI temperature accuracy was primarily attributed to the coarser spatial resolution of the MWRI footprint relative to the AMSR sensors, and other factors described in the following section.

Table 8. Summary of the accuracy of the satellite based daily minimum and maximum air temperature $\left(T_{m n}, T_{m x}\right)$ estimates in relation to independent temperature measurements from 142 global WMO weather stations.

\begin{tabular}{ccccc}
\hline Sensor & $\boldsymbol{R}^{\mathbf{2}} \boldsymbol{T}_{\boldsymbol{m} \boldsymbol{x}}$ & $\boldsymbol{R} \boldsymbol{M S E} \boldsymbol{T}_{\boldsymbol{m} \boldsymbol{x}}$ (Kelvin) & $\boldsymbol{R}^{\mathbf{2}} \boldsymbol{T}_{\boldsymbol{m} \boldsymbol{n}}$ & $\boldsymbol{R} \boldsymbol{M S E} \boldsymbol{T}_{\boldsymbol{m} \boldsymbol{n}}$ (Kelvin) \\
\hline AMSRE & 0.86 & 3.37 & 0.78 & 3.46 \\
AMSR2 & 0.83 & 3.64 & 0.75 & 3.54 \\
MWRI & 0.80 & 4.12 & 0.69 & 4.11 \\
\hline
\end{tabular}


Figure 7. Example correspondence between in-situ daily $T_{m x}$ measurements from $142 \mathrm{WMO}$ validation sites and corresponding temperature estimates from the (a) AMSR-E baseline and (b) calibrated AMSR2 observations.

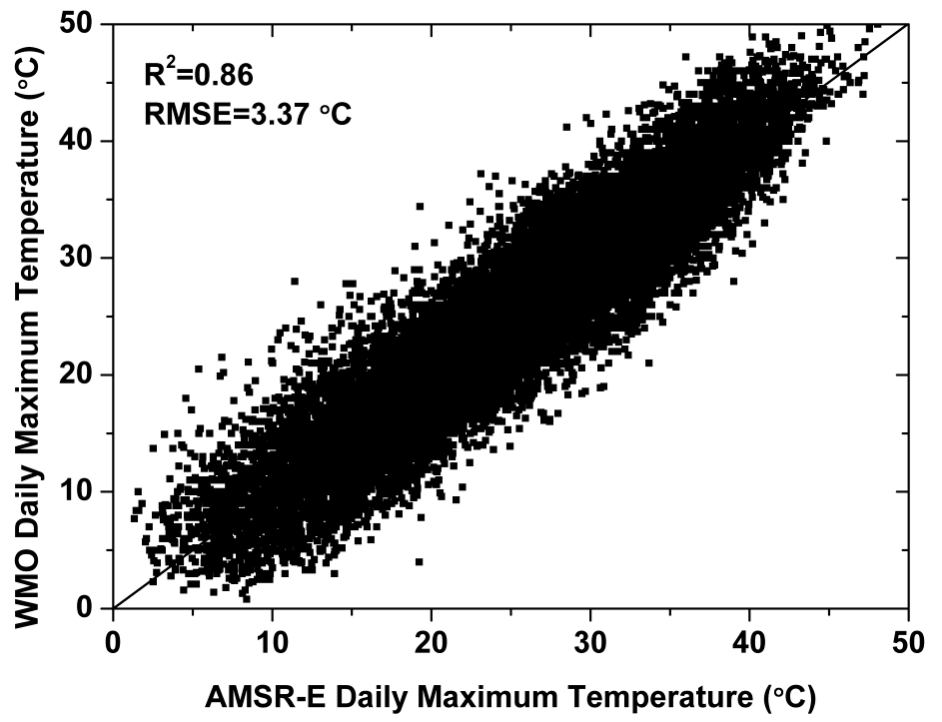

(a)

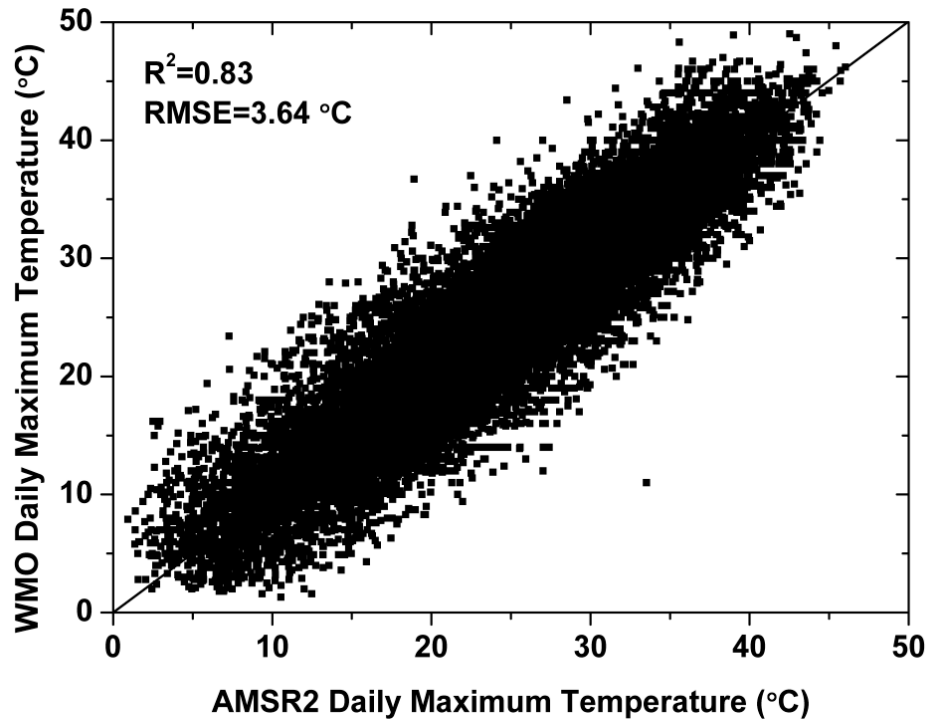

(b)

\subsection{Discussion}

The relative $T_{b}$ bias from AMSR2 was detected, calibrated and mitigated against the AMSR-E baseline. However, slightly lower temperature estimation accuracy from the calibrated AMSR $2 T_{b}$ record was also found. The lower AMSR2 temperature estimation accuracy may reflect a limited $T_{b}$ calibration period represented by the available four-month matched datasets, which do not fully represent potential seasonal or annual changes in the overlapping sensor relationships. As indicated in Subsections 4.2 and 4.3, a number of factors may cause the observation differences between sensors, including different instrument calibrations, differences in spatial coverage (e.g., spatial resolution, geo-location of the footprint center, and footprint sampling), temporal sampling and random uncertainty in the observations. The DD method is capable of minimizing observation biases and partially mitigating the effects of the 
different sensor configurations on the $T_{b}$ retrievals, though the residual impacts of these differences, as well as observation uncertainties inherent to each instrument cannot be completely eliminated using the relatively simple DD inter-calibration method.

The impacts of the inherent differences in sensor observations are also reflected from the lower MWRI performance. Coarser MWRI spatial footprints relative to the other sensors may be the primary factor contributing to lower sensor performance. For example, the $18 \mathrm{GHz}$ channel footprints from AMSR-E and AMSR2 have respective mean spatial resolutions of $21 \mathrm{~km}$ and $18 \mathrm{~km}$, whereas the corresponding MWRI resolution is $39 \mathrm{~km}$, or roughly four times the AMSR footprints. Although the orbital swath observations from the sensors were gridded to a consistent $25 \mathrm{~km}$ resolution global EASE-grid, the resulting $T_{b}$ records after bias correction by the DD method still preserve underlying differences in footprint resolution and sampling from the individual channel frequencies. Moreover, the resampling process itself inevitably causes data losses and its related uncertainties can also affect inter-calibration accuracy.

Future data records with longer overlapping periods and more sophisticated calibrations that consider the inherent differences in sensor configurations, especially different sensor spatial resolutions, would likely improve the accuracy of cross-sensor data integration efforts. Moreover, both MWRI and AMSR2 are relatively new sensors, while AMSR-E encompasses a much longer data record and has undergone multiple data reprocessing events, each with relative improvements over earlier versions. With continuing observations and similar data reprocessing and sensor calibration enhancements, both AMSR2 and MWRI are expected to show improved performance leading to more accurate integrated long-term environmental data records.

\section{Conclusions}

Consistent $T_{b}$ records from similar overlapping satellite microwave sensors provide the basis for generating long-term global land parameter observation records for documenting and diagnosing environmental change. We developed an empirical approach for inter-calibrating AMSR-E and AMSR2 $T_{b}$ records over land using similar overlapping satellite passive microwave observations from the FY3B-MWRI sensor. Our global pixel-wise correlation analysis indicates that the MWRI and AMSR sensor observations are highly correlated $(R>0.95)$ over approximately $27 \%-69 \%$ of the global land area, depending on sensor frequency and polarization. The $T_{b}$ correlation analysis was developed from limited, four-month overlapping MWRI observations with the AMSR2 and AMSR-E sensor records, but indicated significant MWRI and AMSR2 $T_{b}$ biases in relation to the AMSR-E baseline observations. The sensor $T_{b}$ biases vary with channel frequency and polarization, and satellite orbital nodes, though AMSR2 generally produced the highest $T_{b}$ readings while MWRI had the lowest. As a prerequisite for integrating the individual sensor observations into a continuous and consistent data record, empirical linear relationships were established between the AMSR2 and AMSR-E $T_{b}$ retrievals for pixels where both AMSR sensor records were highly correlated $(R>0.95)$ with the overlapping MWRI observations. Pixels not meeting this high correlation requirement generally represented coastal boundaries and other heterogeneous land areas, where the sensor $T_{b}$ relationships were estimated by spatially interpolating regression coefficients from nearby pixels having the same land cover type, but strong sensor correlations. Similar relationships were established between the MWRI and AMSR-E baseline $T_{b}$ observations. The 
AMSR2 and MWRI $T_{b}$ records were then calibrated to the AMSR-E baseline using the DD approach. The resulting calibrated $23 \mathrm{GHz} \mathrm{H}-\mathrm{Pol} T_{b}$ observations from the different sensors were found to be generally consistent with each other for a homogeneous Amazon reference area $(R=0.99$, $R M S E=0.42 \mathrm{~K}$, Bias $=0.04 \mathrm{~K})$ and other $T_{b}$ calibration test regions representing major global climate zones. For the larger global domain, the calibrated AMSR2 and MWRI $T_{b}$ values are comparable with the AMSR-E baseline, with mean biases for the major land cover areas ranging from $-0.81 \mathrm{~K}$ to $0.09 \mathrm{~K}$. We also found no evidence of non-linear variations in the sensor $T_{b}$ relationships, though our analysis was limited by the relatively short, four month overlapping MWRI and AMSR records. The calibrated sensor records were used to obtain daily surface air temperature $\left(T_{m x}, T_{m n}\right)$ estimates using multi-frequency $T_{b}$ inputs and a modified iterative RT retrieval algorithm [7]. The resulting temperature estimates were validated against independent temperature measurements from 142 global weather stations, as a means for further assessing the relative quality and performance of the integrated satellite $T_{b}$ record. The temperature results indicate successful global calibration and integration of the AMSR $T_{b}$ records, and favorable temperature estimation accuracy $\left(R^{2} \geq 0.75, R M S E \leq 3.64{ }^{\circ} \mathrm{C}\right)$, but with lower temperature accuracy from the calibrated MWRI record $\left(R^{2} \geq 0.69, R M S E \leq 4.12{ }^{\circ} \mathrm{C}\right)$. Despite the lower MWRI performance, similar, albeit coarser resolution, overlapping $T_{b}$ observations from this operational sensor generally provide an effective means for harmonizing ongoing AMSR2 observations with the earlier AMSR-E baseline record. The overall $T_{b}$ calibration and temperature estimation accuracy from the integrated satellite record is expected to improve through continuing observations and reprocessing improvements of the MWRI and AMSR2 records.

Multi-frequency passive microwave sensors, including AMSR and MWRI, are less affected by solar illumination and atmosphere constraints relative to optical-infrared sensors and are well-suited for near-daily global monitoring. As indicated in this study, the combined observations from these instruments enable consistent and continuing global environmental monitoring spanning multiple years and satellite data records. Spatially and temporally complementary, multi-frequency $T_{b}$ observations from these instruments also provide a large degree of sensitivity and potential information content for isolating different contributions to the total microwave emission signal, including atmosphere, soil moisture, vegetation and open water effects, enabling land parameter retrievals with favorable accuracy. Finally, our results indicate that synergistic observations from the MWRI and AMSR sensors provide an effective means for developing continuing, long-term global land parameter records with suitable performance and accuracy for global change assessment and monitoring.

\section{Acknowledgments}

The AMSR2 L1R brightness temperature data used for this study were provided courtesy of JAXA. AMSR-E data are produced by Remote Sensing Systems and sponsored by the NASA Earth Science MEaSUREs DISCOVER Project and the AMSR-E Science Team. AMSR-E data were also provided courtesy of the National Snow and Ice Data Center (NSIDC). The WMO weather station data were provided courtesy of the National Climate Data Center (NCDC). This work was conducted at the University of Montana with funding provided by the NASA Terra/Aqua Science and Making Earth System data records for Use in Research Environments (MEaSUREs) programs (NNX11AD46G, NNX14AB20A). 


\section{Author Contributions}

Jinyang Du performed inter-sensor calibrations and air temperature estimations using the integrated satellite data record; John S. Kimball developed the general scheme of the sensor inter-calibration work and contributed substantially to the writing of the manuscript; Jiancheng Shi performed evaluations on the inter-sensor calibration results; Lucas A. Jones developed AMSR-E air temperature estimation algorithms and evaluated the inter-calibration results; Shengli Wu, Ruijing Sun and Hu Yang provided initial processes on MWRI datasets.

\section{Conflicts of Interest}

The authors declare no conflict of interest.

\section{References}

1. Jones, M.O.; Kimball, J.S.; McDonald, K.C.; Jones, L.A. Utilizing satellite passive microwave remote sensing for monitoring global land surface phenology. Remote Sens. Environ. 2011, 115, 1102-1114.

2. Kim, Y.; Kimball, J.S.; Zhang, K.; McDonald, K.C. Satellite detection of increasing northern hemisphere non-frozen seasons from 1979 to 2008: Implications for regional vegetation growth. Remote Sens. Environ. 2012, 121, 472-487.

3. Watts, J.; Kimball, J.S.; Jones, L.A.; Schroeder, R.; McDonald, K.C. Satellite microwave remote sensing of contrasting surface water inundation changes within the Arctic-Boreal region. Remote Sens. Environ. 2012, 127, 223-236.

4. Chuang, T.W.; Henebry, G.M.; Kimball, J.S.; VanRoekel-Patton, D.L.; Hildreth, M.B.; Wimberly, M.C. Satellite microwave remote sensing for mosquito population dynamics. Remote Sens. Environ. 2012, 125, 147-156.

5. Kawanishi, T.J.; Sezai, T.; Ito, Y.; Imaoka, K.; Takeshima, T.; Ishido, Y.; Shibata, A.; Miura, M.; Inahata, H.; Spencer, R.W.; et al. The Advanced Scanning Microwave Radiometer for the Earth Observing System (AMSR-E): NASDA's contribution to the EOS for global energy and water cycle studies. IEEE Trans. Geosci. Remote Sens. 2003, 41, 184-194.

6. Daily Global Land Surface Parameters Derived from AMSR-E, Boulder Colorado USA: National Snow and Ice Data Center. 2010. Available online: http://nsidc.org/data/nsidc-0451.html (accessed on 15 September 2014).

7. Jones, L.A.; Ferguson, C.R.; Kimball, J.S.; Zhang, K.; Chan, S.T.K.; McDonald, K.C.; Njoku, E.; Wood, E. Satellite microwave remote sensing of daily land surface air temperature minima and maxima from AMSR-E. IEEE J. Sel. Top. Appl. Earth Obs. Remote Sens. 2010, 3, 111-123.

8. MEaSUREs Global Record of Daily Landscape Freeze/Thaw Status, Version 02 [1979 to 2010]; National Snow and Ice Data Center: Boulder, CO, USA: 2012. Available online: http://nsidc.org/data/nsidc-0477.html (accessed on 15 September 2014).

9. Jackson, T.J.; Cosh, M.H.; Bindlish, R.; Starks, P.J.; Bosch, D.; Seyfried, M.; Goodrich, D.C.; Moran, M.S.; Du, J. Validation of advanced microwave scanning radiometer soil moisture products. IEEE Trans. Geosci. Remote Sens. 2010, 48, 4256-4272. 
10. Koike, T.; Nakamura, Y.; Kaihotsu, I.; Davva, G.; Matsuura, N.; Tamagawa, K.; Fujii, H. Development of an Advanced Microwave Scanning Radiometer (AMSR-E) algorithm of soil moisture and vegetation water content. Proc. Hydraul. Eng. 2004, 48, 217-222.

11. Mladenova, I.E.; Jackson, T.J.; Njoku, E.; Bindlish, R.; Chan, S.; Cosh, M.H.; Holmes, T.R.H.; de Jeu, R.A.M.; Jones, L.; Kimball, J.; et al. Remote monitoring of soil moisture using passive microwave based techniques - Theoretical basis and overview of selected algorithms for AMSR-E. Remote Sens. Environ. 2014, 144, 197-213.

12. Njoku, E.G.; Chan, S.K. Vegetation and surface roughness effects on AMSR-E land observations. Remote Sens. Environ. 2006, 100, 190-199.

13. Paloscia, S.; Macelloni, G.; Santi, E. Soil moisture estimates from AMSR-E brightness temperatures by using a dual-frequency algorithm. IEEE Trans. Geosci. Remote Sens. 2006, 44, 3135-3144.

14. Kelly, R.E.; Chang, A.T.; Tsang, L.; Foster, J.L. A prototype AMSR-E global snow area and snow depth algorithm. IEEE Trans. Geosci. Remote Sens. 2003, 41, 230-242.

15. Santi, E.; Pettinato, S.; Paloscia, S.; Pampaloni, P.; Fontanelli, G.; Crepaz, A.; Valt, M. Monitoring of Alpine snow using satellite radiometers and artificial neural networks. Remote Sens. Environ. 2014, 144, 179-186.

16. Tedesco, M.; Narvekar, P.S. Assessment of the NASA AMSR-E SWE product. IEEE J. Sel. Top. Appl. Earth Obs. Remote Sens. 2010, 3, 141-159.

17. Kimball, J.S.; Jones, L.A.; Zhang, K.; Heinsch, F.A.; McDonald, K.C.; Oechel, W.C. A satellite approach to estimate land-atmosphere $\mathrm{CO}_{2}$ exchange for Boreal and Arctic biomes using MODIS and AMSR-E. IEEE Trans. Geosci. Remote Sens. 2009, 47, 569-587.

18. Meissner, T.; Wentz, F. Intercalibration of AMSR-E and Windsat brightness temperature measurements over land scenes. In Proceedings of the IEEE International Geoscience and Remote Sensing Symposium, Honolulu, HI, USA, 25-30 July 2010; pp. 3218-3219.

19. Mu, Q.; Jones, L.A.; Kimball, J.S.; McDonald, K.C.; Running, S.W. Satellite assessment of land surface evapotranspiration for the pan-Arctic domain. Water Resour. Res. 2009, 45, doi:10.1029/2008WR007189.

20. Jones, M.O.; Kimball, J.S.; Jones, L.A.; McDonald, K.C. Satellite passive microwave detection of North America start of season phenology. Remote Sens. Environ. 2012, 123, 324-333.

21. Tuttle, S.E.; Salvucci, G.D. A new approach for validating satellite estimates of soil moisture using large-scale precipitation: Comparing AMSR-E products. Remote Sens. Environ. 2014, 142, 207-222.

22. Imaoka, K.; Takashi, M.; Misako, K.; Marehito, K.; Norimasa, I.; Keizo, N. Status of AMSR2 instrument on GCOM-W1, earth observing missions and sensors: Development, implementation, and characterization II. Proc. SPIE 2012, 852815, doi:10.1117/12.977774.

23. Colton, M.; Poe, G. Intersensor calibration of DMSP SSM/I's: F-8 to F-14, 1987-1997. IEEE Trans. Geosci. Remote Sens. 1999, 37, 418-439.

24. Yang, S.; Weng, F.; Yan, B.; Sun, N.; Goldberg, M. Special Sensor Microwave Imager (SSM/I) intersensor calibration using a simultaneous conical overpass technique. J. Appl. Meteorol. Climatol. 2011, 50, 77-95.

25. Wentz, F.; Ashcroft, P.; Gentemann, C. Post-launch calibration of the TRMM microwave imager. IEEE Trans. Geosci. Remote Sens. 2001, 39, 415-422. 
26. Biswas, S.; Farrar, S.; Gopalan, K.; Santos-Gracia, A.; Jones, W.L.; Billanow, S. Intercalibration of microwave radiometer brightness temperatures for the global precipitation measurement mission. IEEE Trans. Geosci. Remote Sens. 2013, 51, 1465-1477.

27. Chander, G.; Hewison, T.J.; Fox, N.; Wu, X.; Xiong, X.; Blackwell, W. Overview of inter-calibration of satellite instruments. IEEE Trans. Geosci. Remote Sens. 2013, 51, 1056-1080.

28. GPM X-Cal Results for AMSR2. Available online: http://smsc.cnes.fr/MEGHAT/XCAL-Workshop/ XCal_Toulouse_AMSR2.pdf (accessed on 1 April 2014).

29. Results of Intercalibration between AMSR2 and TMI/AMSR-E. Available online: http://suzaku. eorc.jaxa.jp/GCOM_W/materials/product/AMSR2_XcalResults_1-1.pdf (accessed on 1 April 2014).

30. Yang, H.; Weng, F.; Lv, L.; Lu, N.; Liu, G.; Bai, M.; Qian, Q.; He, J.; Xu, H. The FengYun-3 microwave radiation imager on-orbit verification. IEEE Trans. Geosci. Remote Sens. 2011, 49, 4552-4560.

31. Imaoka, K.; Kachi, M.; Kasahara, M.; Ito, N.; Nakagawa, K.; Oki, T. Instrument performance and calibration Of AMSR-E and AMSR2. In Proceedings of ISPRS Commission VIII Mid-Term Symposium "Networking the World with Remote Sensing", Kyoto, Japan, 9-12 August 2010; Volume XXXVIII, Part 8.

32. Algorithm Theoretical Basis Document, AMSR Level 2A Algorithm; RSS Technical Report 121 599B-1; Santa Rosa, CA, USA, 1999. Available online: https://nsidc.org/data/amsre/pdfs/ amsr_atbd_level2a.pdf (accessed on 1 April 2014).

33. Armstrong, R.L.; Brodzik, M.J. An earth-gridded SSM/I data set for cryospheric studies and global change monitoring. Adv. Space Res. 1995, 16, 155-163.

34. Das, N.N.; Colliander, A.; Chan, S.K.; Njoku, E.G.; Li, L. Intercomparisons of brightness temperature observations over land from AMSR-E and WindSat. IEEE Trans. Geosci. Remote Sens. 2014, 52, 452-464.

35. Justice, C.O.; Townshend, J.R.G.; Vermote, E.F.; Masuoka, E.; Wolfe, R.E.; Saleous, N.; Roy, D.P.; Morisette, J.T. An overview of MODIS land data processing and product status. Remote Sens. Environ. 2002, 83, 3-15.

36. Yang, H.; Zou, X.; Li, X.; You, R. Environmental data records from FengYun-3B microwave radiation imager. IEEE Trans. Geosci. Remote Sens. 2012, 50, 4986-4993.

37. Bristow, K.L.; Campbell, G.S. On the relationship between incoming solar radiation and daily maximum and minimum temperature. Agric. For. Meteorol. 1984, 31, 159-166.

38. Dickinson, R.E. Land surface processes and climate modeling. Bull. Am. Meteorol. Soc. 1996, 76, 1445-1448.

39. Liang, H. Inter-Satellite Microwave Radiometer Calibration. Ph.D. Dissertation, University of Central Florida, Orlando, FL, USA, 2008.

(C) 2014 by the authors; licensee MDPI, Basel, Switzerland. This article is an open access article distributed under the terms and conditions of the Creative Commons Attribution license (http://creativecommons.org/licenses/by/3.0/). 